On Course. Richard Whiteman Quartet. [Toronto]: [s.n.], 2012. 1 compact disc (77:00). Performers: Richard Whiteman, bass; Reg Schwager, guitar; Amanda Tosoff, piano; Morgan Childs, drums. You (3:46) - Come Rain or Come Shine (5:37) - Down With It (4:23) - Dream (4:53) - This Time the Dream's on Me (4:54) - Cottontail (4:36) - Looking at You (5:03) - HalfSteps (5:42) - There's a Small Hotel (5:07) - Use Your Imagination (4:30) - Who Knows (3:56) Passion Flower (4:51) - Lullaby of the Leaves (4:45) - Amanda's Blues (4:51) - Just Another Boy and Girl (2:58) - West Indian Pancake (3:13) - After You've Gone (4:12). \$15.00. Order from: http://www.indiepool.com/RWH2012CD12.

Richard Whiteman has been a mainstay of the Toronto jazz scene for the past couple of decades as an extremely capable and versatile piano player. He can be seen playing in solo, trio and quartet settings, as well as in various musicals around the city. Whiteman is also a favourite accompanist of many of Toronto's jazz singers, such as Heather Bambrick and Dee Daniels.

In the past few years Whiteman has also taken up the bass, and has decided to document his newfound talent in the form of this independently produced album called On Course. Filling out the ensemble are three musicians - guitarist Reg Schwager, pianist Amanda Tosoff, and drummer Morgan Childs-who demonstrate an impressive amount of musical sympathy with each other. The result is a highly refined sound reminiscent of post-bop era trios such as Wynton Kelly's.

The opening track, a Latin original entitled "You," sets the tone for the album with its length and the conciseness of the solos. The composition is a standard A-A-B-A form comprised of thirty-two bars, but what is striking from the very first bar is the group's ability to maintain a swinging sensibility in a Latin song. The feeling of propulsion, calm yet intense, that comes from Whiteman and Childs is truly special. This feeling never flags throughout the sixteen tracks that follow, making the entire album easily digestible in one sitting.

Tosoff, who takes turns with Schwager in playing the lead melody, has a commanding presence on each piece in the album. Many of the songs have Tosoff playing the melody with her right hand, while Schwager comps in the background. She even takes entire solos without playing a single chord in the left hand. It takes discipline to treat a melody, let alone a solo, from the standpoint of a monophonic instrument. Her approach demonstrates refinement and maturity. "There's a Small Hotel" is a wonderful example of her ability to shine in a short span of time, relying on tasteful melodic choices and an impeccable sense of swing.

The "economic" sensibility of the album puts Schwager in a comfortable setting that manifests itself in a sense of play, particularly in compositions such as Duke Ellington's "Cottontail." On this track we hear Schwager using what solo time he has to great effect with bebop lines 
composed of stunning symmetry and melody. In between all of this is a peppering of rhythms that coaxes a similar impishness out of Childs. The interplay that ensues in this moment and others like it is one of the brightest features of the album.

It's worth noting how difficult it is for harmonic instruments like piano and guitar to complement each other. There's nowhere for either to hide, so their efforts must be coordinated and tempered with some intense listening. That these two players never step on each other's toes testifies to their musicality.

Childs plays an exemplary supporting role on this album. He never really gets a chance to stretch out except for a few songs where he trades fours with the other band members, and on the out chorus of "Cottontail," where he takes the helm for the improvised bridge section. The rhythms that Childs creates with Whiteman are compelling. It cannot be overstated how much the synergy of drummer and bassist sets up everyone else to succeed. An excellent example of this occurs in "Who Knows," where the piano solo is propelled by a driving, walking bass line and brushwork on the snare. The fact that Tosoff is sparse with her harmonic accompaniment showcases the dynamic between Whiteman and Childs.

With Whiteman coming from a piano background, one could be forgiven for expecting him to play with more of a dramatic flair. However, on this album he is a rock: his bass lines rarely, if ever, stray from playing quarter notes. One of the few solos Whiteman takes is in "Use Your Imagination." Although he acquits himself well, it is his role of supporting player that really speaks to the listener. The swing tunes such as "Lullaby of the Leaves" show him driving the time and swing. Whiteman and Childs must have spent a good amount of time playing together because the bass lines and hi-hat rhythms are locked in tighter than a Chinese finger puzzle!

Taken as a whole, On Course could serve as a textbook on how to approach the trio or quartet format. Beginner and intermediate players of piano and guitar will also learn a great deal about how to function in groups with more than one polyphonic instrument. This is a stellar outing, and Whiteman also does a good job of instilling a sense of jealousy in those of us who struggle to be proficient in one instrument, let alone tackling another. I highly recommend this album.

\section{Michael McArthur}

Northern Ontario School of Medicine 